Herz 2020 · 45:334

https://doi.org/10.1007/s00059-020-04926-y

Published online: 30 April 2020

(c) Springer Medizin Verlag $\mathrm{GmbH}$, ein Teil von Springer Nature 2020

Junbo Ge

Dept. of Cardiology, Zhongshan Hospital, Fudan University, Shanghai, China

\title{
Initial resolution of the COVID-19 pandemic in China-can the virus return?
}

especially international metropoles such as Shanghai, is facing great pressure to prevent imported cases and the rebound of the epidemic.

Another challenge is the transmission by asymptomatic carriers [4]. One study has reported that the viral load detected in asymptomatic patients was similar to that in symptomatic patients, which also theoretically suggests the potential transmission by asymptomatic patients [5]. Therefore, it is necessary to carry out nucleic acid tests against the virus in the acute phase and antibody tests to determine the response by the individual's own immune system after infection to know how many asymptomatic infections have occurred. For asymptomatic patients it is important to try to clarify the period and the dynamics of virus release. It will be helpful to detect and control the new clustering infection in time.

Although China has made some achievements in the previous stage, we still face a huge risk of a second wave of COVID-19 outbreaks in the near future. The number of patients infected by COVID-19 has been limited in most regions of China, except for Wuhan. Therefore, theoretically there is the possibility of a new round of virus infection due to a lack of immunity. The definite number of infected cases ultimately depends on the infectivity of the virus itself and the prevention and control measures taken by the public. It has already been reported by the official media that a vaccine against COVID-19 was developed successfully. A phase I study of 108 healthy participants showed no side effect. Subsequent investigations should be focused on the effectiveness to acquire immunity against this specific coronavirus. To eradicate the transmission of this virus, isolation of the sources of infection and a cut-off of the transmission routes are too costly and practically impossible in the long run. Acquired immunity by vaccination or by past infection seems to be the final solution for this pandemic.

\section{Corresponding address}

Prof. Dr. med. Junbo Ge

Dept. of Cardiology, Zhongshan Hospital, Fudan University

180 Fenglin Road, 200032 Shanghai, China ge.junbo@zs-hospital.sh.cn

Conflict of interest. J. Ge declares that he has no competing interests.

\section{References}

1. Lu H, Stratton CW, Tang YW (2020) Outbreak of pneumonia of unknown etiology in Wuhan, China: The mystery and the miracle. J Med Virol 92:401-402

2. Park SE (2020) Epidemiology, virology, and clinical features of severe acute respiratory syndrome -coronavirus-2 (SARS-CoV-2; Coronavirus Disease19). Clin Exp Pediatr. https://doi.org/10.3345/cep. 2020.00493

3. Ceraolo C, Giorgi FM (2020) Genomic variance of the 2019-nCoV coronavirus. J Med Virol 92:522-528

4. Yu X, Yang R (2020) COVID-19 transmission through asymptomatic carriers is a challenge to containment. Influenza Other Respir Viruses. https://doi.org/10.1111/irv.12743

5. Zou L, Ruan F, Huang M et al (2020) SARSCcoV-2 viral load in upper respiratory specimens of infected patients. N Engl J Med 382:1177-1179 